\title{
Efeito de medicamentos indicados para a prevenção da mastite bovina no período seco sobre a função fagocítica in vitro de leucócitos do leite de caprinos ${ }^{1}$
}

\author{
Alexandre Q. Benesi ${ }^{2}$, Melissa Hartman ${ }^{3 \star}$, Milton R. Azedo ${ }^{3}$, Camila F. Batista ${ }^{3}$, \\ Maiara G. Blagitz ${ }^{3}$, Fernando José Benesi ${ }^{4}$ e Alice Maria M.P. Della Libera ${ }^{4}$
}

\begin{abstract}
Benesi A.Q., Hartman M., Azedo M.R., Batista C.F., Blagitz M.G., Benesi F.J. \& Della Libera A.M.M.P. 2010. [Effect of dry cow therapy products on the in vitrophagocytic function of goat milk leukocytes.] Efeito de medicamentos indicados para a prevenção da mastite bovina no período seco sobre a função fagocítica in vitro de leucócitos do leite de caprinos. Pesquisa Veterinária Brasileira 30(5):385-388. Departamento de Clínica Médica, Faculdade de Medicina Veterinária e Zootecnia, Universidade de São Paulo, Av. Prof. Dr. Orlando Marques de Paiva 87, São Paulo, SP 05508-270, Brazil. E-mail: hartman @ usp.br

The use of specific anti-mastitis drugs is indicated in dry cow therapy to prevent infections in the following lactation. Nonetheless, cells active in the dry period are of fundamental importance for the involution of the mammary gland and its recovery for the following lactation. Since there are no specific drugs for dry goat therapy, the dry cow therapy drugs tend to be misused in goats despite of the anatomical and physiological differences apart from the particularities of the two species. The objective of the present study was to evaluate the influence of five drugs specific for dry cow therapy on the function of goat milk phagocytes. Somatic cells were isolated from 20 milk samples of 10 lactating goats that had not been treated for mastitis during the previous 30 days. Milk samples were collected properly and microbiological culture yielded negative results. Cells adherent to glass coverslips were treated with commercially available dry cow therapy drugs containing active principles such as Gentamicin (M1), Cephalonium anhydrous (M2), Ampicillin (M3), Cloxacillin benzathine (M4) and Cephapirin benzathine (M5). Phagocytosis of Zymosan particles was evaluated. Mean phagocytosis indexes of cells treated with M2 (15.12\% \pm 16.22$), \mathrm{M} 3(6.02 \% \pm 7.96), \mathrm{M} 4(4.54 \% \pm 5.45)$ and M5 $(2.47 \% \pm 4.64)$ were lower $(\mathrm{p}<0.001)$ than mean phagocytosis index of the control group $(40.67 \% \pm 19.68)$. Mean phagocytosis index of cells treated with M2 was greater $(p<0.05)$ than those treated with M3, M4 and M5, whereas means of the latter three treatments were statistically similar. M1-treated cells did not adhere adequately to the cover slips, making it impossible to evaluate phagocytosis in this group. The results obtained enable the conclusion that drugs used affected milk phagocytes negatively. However, interference on somatic cell function is not the sole factor determining an unsuccessful dry period therapy, since the efficacy of the active principle on pathogens responsible for infectious processes also has to be considered.
\end{abstract}

INDEX TERMS: Mastitis, milk, goat, phagocytosis.

\footnotetext{
${ }^{1}$ Recebido em 3 de junho de 2009.

Aceito para publicação em 16 de dezembro de 2009.

${ }^{2}$ Graduando em Medicina Veterinária, Faculdade de Medicina Veterinária e Zootecnia (FMVZ), Universidade de São Paulo (USP), Av. Prof. Dr. Orlando Marques de Paiva 87, Cidade Universitária, São Paulo, SP 05508-270, Brasil.

${ }^{3}$ Pós-Graduando do Programa de Clínica Médica, FMVZ-USP, São Paulo, SP. *Autor para correspondência: hartman@usp.br

${ }^{4}$ Departamento de Clínica Médica, FMVZ-USP, São Paulo, SP.
}

RESUMO.- O uso de medicamentos antimamíticos específicos para vacas no período seco é indicado para prevenção de infecções na lactação seguinte. Não obstante, a ação das células envolvidas no período de secagem tem fundamental importância para a involução da glândula mamária e seu restabelecimento para a lactação subseqüente. A indisponibilidade de tais medicamentos para uso em cabras tem resultado na extrapolação do uso de produtos recomendados para vacas sem que se con- 
siderem as particularidades e diferenças anátomo-fisiológicas entre as espécies bovina e caprina. O presente estudo teve por objetivo avaliar a influência de cinco antimamíticos específicos para vacas secas sobre a função dos fagócitos provenientes de leite caprino. Para tal, fez-se o isolamento de células somáticas de 20 amostras de leite provenientes de 10 cabras lactantes, sem antecedentes de tratamento de mamite nos últimos 30 dias, sob condições higiênico-sanitárias de colheita e com resultados negativos ao cultivo microbiológico do leite. As células aderidas a lamínulas de vidro foram confrontadas com formulações contendo princípios ativos disponíveis no mercado como Gentamicina (M1), Cefalônio Anidro (M2), Ampicilina (M3), Cloxacilina Benzatínica (M4) e Cefapirina Benzatínica (M5). Avaliou-se, por microscopia, a fagocitose de partículas de Zymosan. As médias dos índices de fagocitose das células submetidas ao tratamento com M2 $(15,12 \% \pm$ $16,22), \mathrm{M} 3(6,02 \% \pm 7,96), \mathrm{M} 4(4,54 \% \pm 5,45)$ e M5 $(2,47 \% \pm$ $4,64)$ foram menores $(p<0,001)$ que a média dos índices de fagocitose do grupo controle $(40,67 \% \pm 19,68)$. A média dos índices de fagocitose das células submetidas ao tratamento com M2 foi maior $(p<0,05)$ que as médias dos tratamentos com M3, M4 e M5 enquanto estas foram estatisticamente iguais entre si. As amostras celulares submetidas ao medicamento M1 exibiram adesão insuficiente ou ausente às lamínulas, inviabilizando a avaliação da fagocitose por meio da técnica utilizada. Os resultados obtidos permitem concluir que os medicamentos estudados exerceram influência negativa sobre os fagócitos do leite, porém, esta interferência sobre as funções das células somáticas não pode por si só determinar o insucesso da terapia proposta para o período seco, pois deve ser considerada, outrossim, a eficácia do princípio ativo sobre o patógeno causador do processo infeccioso.

TERMOS DE INDEXAÇÃO: Mastite, leite, cabra, fagocitose.

\section{INTRODUÇÃO}

A inexistência de formulações antimamíticas de fase seca específicas para a espécie caprina conduz à extrapolação do uso de medicamentos indicados para bovinos em caprinos. É conhecido o fato de que estes medicamentos, em bovinos, podem ter influência negativa sobre a capacidade fagocitária das células somáticas do leite (Nickerson et al. 1986, Lintner \& Eberhart 1990, Batista et al. 2006). Para tratamento de mamite são preconizados diversos protocolos, o que se explica pela freqüência com que as glândulas mamárias manifestam refratariedade à terapia, mesmo nos casos de comprovada sensibilidade in vitro ao agente etiológico isolado e ao antimicrobiano empregado. O êxito do tratamento não depende somente da sensibilidade do agente infeccioso ao antimicrobiano, mas também da interação hospedeiro-parasita, das condições do hospedeiro e correspondente mecanismo de defesa (International Dairy Federation 2003).

A fagocitose, responsável pela primeira linha de defesa contra microrganismos invasores, é realizada por células que se distribuem basicamente em dois sistemas, o sistema mielóide, do qual fazem parte os neutrófilos, e o sistema mononuclear fagocitário, composto pelos macrófagos (Tizard
2004). Os fagócitos, assim denominados os neutrófilos e macrófagos, possuem papel primordial na eliminação de patógenos causadores de moléstias, função que pode ser comprometida pela ação de antibióticos e medicamentos antimamíticos (Dosogne et al. 1998). Assim que a fagocitose é deflagrada, inicia-se a mobilização dos mecanismos bactericidas dependentes e independentes de oxigênio fundamentais para a defesa da glândula mamária (Rainard \& Poutrel 2000). Lintner \& Eberhart (1990) demonstraram que a fagocitose de Staphylococcus aureus por neutrófilos provenientes de leite de vacas se apresentava reduzida quando os medicamentos testados estavam associados com gordura e nata. Além disso, tem-se verificado que a interferência na fagocitose depende da concentração dos medicamentos utilizados, do agente envolvido no processo infeccioso, das condições em que o estudo é realizado (in vitro ou in vivo), da técnica empregada e da procedência das células, pois segundo Paape et al. (1996) e Tian et al. (2005) existem diferenças na expressão dos receptores na superfície das células de defesa constituintes do sangue e do leite. Estudos indicam que a utilização de antibioticoterapia para tratamento de cabras no período seco tem se demonstrado eficaz na diminuição da incidência de novas infecções intramamárias (Gonzalo et al. 2004, McDougal \& Anniss 2005). O presente estudo objetivou avaliar a interferência de formulações para tratamento/prevenção de mastites em vacas secas sobre a função fagocítica de macrófagos presentes no leite de cabras, através da técnica de fagocitose in vitro.

\section{MATERIAL E MÉTODOS}

Foram selecionadas 10 cabras da raça Saanen em lactação, as quais foram isentas de tratamento intramamário nos 30 dias precedentes à colheita e negativas ao cultivo microbiológico do leite. Foram coletados aproximadamente $200 \mathrm{~mL}$ de leite de cada teto. O total de 20 amostras foram acondicionadas em frascos plásticos do tipo Falcon de $50 \mathrm{~mL}$ e mantidos sob refrigeração $\left(4^{\circ} \mathrm{C}\right)$ para subseqüente processamento no Laboratório de Imunodiagnóstico da Faculdade de Medicina Veterinária e Zootecnia, Universidade de São Paulo, São Paulo, SP. As amostras de leite foram previamente diluídas em solução PBS (Phosphate Buffered Saline) (1:1) e centrifugadas a $500 \mathrm{G}$ durante 20 minutos a $4^{\circ} \mathrm{C}$. O sobrenadante, constituído principalmente de gordura, foi descartado, e o botão de células formado na superfície inferior do frasco preservado e seguidamente desprendido com aspersão gentil de PBS refrigerado. Os frascos foram completados para o volume de $50 \mathrm{~mL}$ com PBS e submetidos a uma segunda centrifugação, seguindo-se os mesmos procedimentos, desprezo do sobrenadante e suspensão dos botões celulares em $1 \mathrm{~mL}$ de PBS. Fez-se, então, um pool celular com transferência das suspensões de células de cada frasco para um único, que foi novamente centrifugado para obtenção final do botão, posteriormente acrescido de $5 \mathrm{~mL}$ de RPMI 1640 para preservação da integridade celular. Para determinação da concentração e viabilidade celular, $10 \mu \mathrm{L}$ da suspensão das células em $5 \mathrm{~mL}$ de RPMI 1640 foram adicionados a $90 \mu \mathrm{L}$ de solução de azul de tripan a $0,1 \%{ }^{5}$ e realizada a contagem dos leucócitos em câmara de Neubauer, sob microscopia óptica ${ }^{6} \mathrm{com}$ aumento de 400 vezes. O número total de células nos quadrantes se referiu à concentração celular da suspensão celular 1 e o resultado foi fornecido em nú- 
mero de células $/ \mathrm{mm}^{3}$, posteriormente convertido em número de células $/ \mathrm{mL}$. Para a execução das provas foi calculado o índice de viabilidade (concentração de células que não incorporaram o azul de tripan). O volume foi ajustado para obtenção de $2 \times 10^{6}$ células/mL (suspensão celular 2). Medicamentos com os princípios-ativos Gentamicina (M1), Cefalônio Anidro (M2), Ampicilina (M3), Cloxacilina Benzatínica (M4) e Cefapirina Benzatínica (M5) foram adicionados, separadamente, a uma alíquota da suspensão celular 2, a qual denominou-se, então, suspensão celular 3 . O volume do medicamento adicionado à suspensão celular 2 foi equivalente a $1 /$ 200 da dose recomendada pelo fabricante para um quarto mamário bovino, recomendado pelo fabricante. O medicamento foi previamente diluído 1:1 em RPMI 1640. A suspensão celular 3 permaneceu em estufa à $37^{\circ} \mathrm{C}$, durante uma hora e procedeu-se novo teste de viabilidade celular.

Nos poços de placas de poliestireno ${ }^{7}$ (24 poços de $16 \mathrm{~mm}$ de diâmetro) foram colocadas lamínulas de vidro de $13 \mathrm{~mm}$ de diâmetro, e sobre estas, alíquotas de $200 \mathrm{~mL}$ da suspensão celular 3. Após duas horas em temperatura ambiente, as lamínulas foram lavadas duas vezes com 1,0mL de RPMI 1640 enriquecido com $10 \%$ de soro fetal bovino. A primeira coluna de poços foi utilizada como controle com adição da suspensão celular 2 e de parede de células mortas de Saccaromyces cerevisiae ${ }^{8}$ As colunas $2,3,4,5$ e 6, cada uma correspondente a um medicamento, receberam alíquotas de suspensão celular $3 \mathrm{com}$ Zymosan. As amostras foram plaqueadas em duplicata. Após a adição de mais $500 \mu \mathrm{L}$ de RPMI 1640 com 10\% de soro fetal bovino e de $3 \mu \mathrm{L}$ de Zymosan por poço, as placas foram fechadas, as suspensões celulares homogeneizadas e incubadas a $37^{\circ} \mathrm{C}$, durante uma hora. Subsequentemente procedeu-se a lavagem dos poços com $1000 \mu \mathrm{L}$ de RPMI $1640 \mathrm{com} 10 \%$ de soro fetal bovino e a fixação com $200 \mu \mathrm{L}$ de solução de glutaraldeído, durante 10 minutos, além do acréscimo de $1,0 \mathrm{~mL}$ de água Milli-Q. Foram feitas as leituras das lamínulas em microscopia de contraste de fase ${ }^{9}$ com aumento de 600 vezes e os resultados obtidos foram expressos em porcentagem de células que fagocitaram as partículas de Zymosan (Fig.1). A normalidade da distribui-

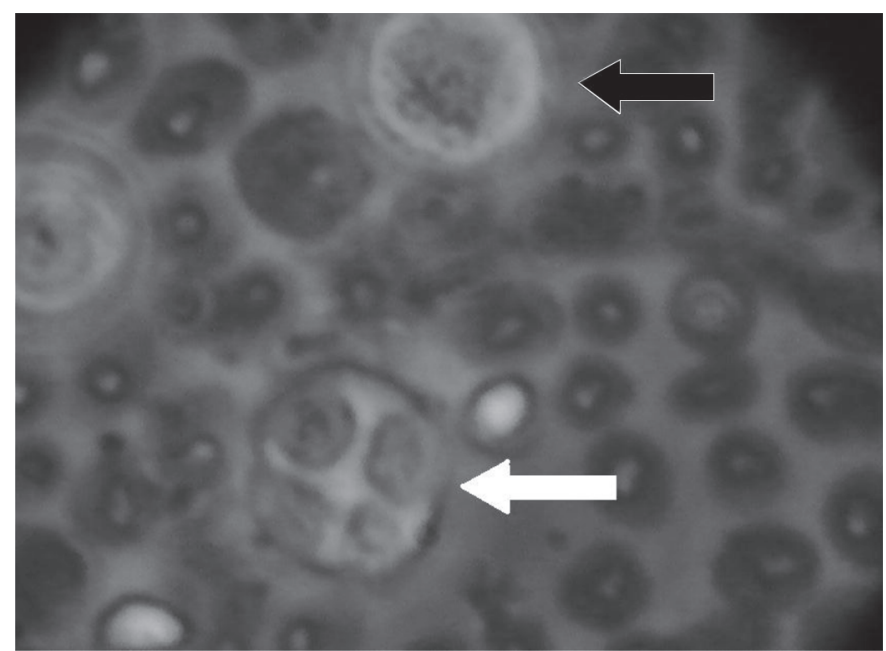

Fig.1. Fagócitos lácteos de cabra. Seta escura indicando célula que não fagocitou partícula de Zymosan. Seta clara indicando 4 partículas de Zymosan fagocitadas. Microscopia de contraste de fase, 600x.
Quadro 1. Média ( \pm desvio padrão) do índice de fagocitose (\%) de células provenientes do leite de cabra, submetidas a diferentes medicamentos antimamíticos aplicáveis no período seco de vacas

\begin{tabular}{lccccc}
\hline \multicolumn{5}{c}{ Tratamento } \\
\cline { 2 - 6 } & Controle & M2 & M3 & M4 & M5 \\
\hline Índice de & 40,67 & 15,12 & 6,02 & 4,54 & 2,47 \\
Fagocitose & $( \pm 19,68)^{\mathbf{a}}$ & $( \pm 16,22)^{\mathbf{b}}$ & $( \pm 7,96)^{\mathbf{c}}$ & $( \pm 5,45)^{\mathbf{c}}$ & $( \pm 4,64)^{\mathbf{c}}$
\end{tabular}

Médias com letras diferentes indicam diferenças estatísticas com $p<0,001$, em comparações com o grupo controle, e $p<0,05$, nas comparações entre tratamentos, por meio do Teste-T pareado.

M2 - Cefalônio Anidro.

M3 - Ampicilina.

M4 - Cloxacilina Benzatínica.

M5 - Cefapirina Benzatínica.

ção dos dados foi verificada através do teste de AndersonDarling e as amostras comparadas pelo teste T-pareado, aplicado por software estatístico ${ }^{10}$.

\section{RESULTADOS E DISCUSSÃO}

A fagocitose é um mecanismo de defesa fundamental na eliminação de microrganismos causadores de moléstias. Tal fato deve ser considerado uma vez que a eficácia do tratamento de infecções intramamárias não depende apenas do medicamento e do patógeno em questão, mas sim da associação destes com os fatores inerentes ao animal (International Dairy Federation 2003, Tizard 2004). Conforme apresentado no Quadro 1, os índices de fagocitose das células submetidas aos tratamentos com as formulações M3, M4 e M5 não apresentaram diferenças estatísticas entre si, no entanto, o índice de fagocitose das células submetidas ao tratamento com M2 foi menor do que o observado no controle e maior que nos três primeiros citados. As células submetidas ao tratamento M1 tiveram adesão insuficiente ou ausente às lamínulas, portanto não tiveram seu índice de fagocitose mensurado. Embora através de técnicas e preparações diversas daquelas aplicadas no presente estudo, investigações prévias relatam o efeito negativo de medicamentos sobre mecanismos de defesa mamários de vacas (Nickerson et al. 1986, Paape et. al. 1996). Dosogne et al. (1998) não observaram interferência na capacidade fagocítica in vitro dos fagócitos sanguíneos expostos a doses terapêuticas de cefapirina e mecilinamina.

A comparação dos índices de fagocitose de células provenientes do leite de vacas submetidas a preparações à base de cefalônio anidro e cloxacilina benzatínica com os resultados aqui apresentados sugere que, em ambos, a cloxacilina resultou em índice de fagocitose médio menor que o encontrado no grupo controle (Batista et al. 2006). Diferentemente dos resultados obtidos por Batista et al. (2006), em que não

\footnotetext{
${ }^{5}$ Merck $^{\circledR}$.

6 Microscópio Olympus ${ }^{\circledR}$

7 COSTAR $^{\circledR} 3424$.

8 Zymosan Sigma ${ }^{\circledR}$.

${ }^{9} \mathrm{Nikon}^{\circledR}$

${ }^{10}$ Minitab $^{\circledR}$
} 
houve diferença estatística entre o tratamento com cefalônio anidro e o controle, as amostras de células do estudo em questão relataram índices de fagocitose menores que os do controle quando submetidas ao cefalônio anidro. Batista et al. (2006) relatam, ainda, que a gentamicina proporcionou o menor índice de fagocitose dentre os demais medicamentos avaliados, concordando com Nickerson et al. (1986) e Hoeben et al. (1997). Tal comparação não foi possível neste estudo, uma vez que não houve adesão suficiente de células para confrontar com o medicamento. A discrepância entre os resultados de diferentes trabalhos poderia ser explicada não pelo principio ativo, mas pelas características do veículo utilizado na formulação. Os medicamentos utilizados neste estudo continham veículo oleoso e, portanto apresentaram lenta liberação do princípio ativo e aspecto gorduroso, porém não havia especificações da composição destes veículos. Paape et al. (2004) relataram que glóbulos de gordura do leite caprino reduziam os índices de fagocitose de Staphylococcus aureus por polimorfonucleados sangüíneos, supostamente explicando os resultados com as formulações estudadas.

No que se diz respeito à susceptibilidade a infecções intramamárias durante o período seco, a espécie caprina não se comporta como a bovina, a qual se encontra mais susceptível a mamite infecciosa neste período (Anderson et al. 2005, Contreras et al. 2007). É sabido que na espécie caprina existem índices de auto-cura independentes da aplicação de formulações antimicrobianas na secagem (Fox et al. 1992), questionando-se a administração de medicamentos de fase seca nestes animais. Em contrapartida, McDougal \& Annis (2005) observaram que a terapia antibiótica na secagem reduz significativamente a incidência de infecções da glândula mamária em cabras. Em termos práticos, a infusão intramamária de antibióticos tem valor terapêutico na espécie caprina durante o processo de secagem (Anderson et al. 2005) com resultados comprovados (Fox et al. 1992). Convém salientar que o êxito do tratamento da mamite é considerado multifatorial, devendo-se avaliar as variações inerentes ao tratamento instituído, ao patógeno a ser eliminado e ao animal em questão (Costa 2006). Tais fatores não devem ser reputados separadamente (Crispie et al. 2004, Barkema et al. 2006).

\section{CONCLUSÃO}

As formulações medicamentosas específicas para vacas secas não foram inócuas e influenciaram negativamente a capacidade fagocitária in vitro dos leucócitos presentes em amostras de leite da cabra.

\section{REFERÊNCIAS}

Anderson D.E., Hull B.L. \& Pugh D.G. 2005. Enfermidades da Glândula Mamária, p.380-399. In: Pugh D.G. (Ed.), Clínica de Ovinos e Caprinos. Roca, São Paulo.

Barkema H.W., Schukken Y.H. \& Zadoks R.N. 2006. Invited review:
The role of cow, pathogen, and treatment regimen in the therapeutic success of bovine Staphylococcus aureus mastitis. J. Dairy Sci. 89:1877-1895.

Batista C.F., Azedo M.R., Blagitz M.G., Stricagnolo C.R., Sucupira M.C.A., Pontes E.O. \& Della Libera A.M.M.P. 2006. Innocuousness of commercial drugs indicated for the treatment of bovine mastitis in the dry period on phagocytosis of milk leukocytes. Revta Ciênc. Vet. 4(4):17.

Contreras A., Sierra D., Sanches A., Corrales J.C., Marco J.C., Paape M.J. \& Gonzalo C. 2007. Mastitis in small ruminants. Small Rumin. Res. 68:145-153.

Costa E.O. 2006. Uso de antimicrobianos na mastite, p.501-515. In: Spinosa H.S., Gorniak S.L. \& Bernardi M.M. (Eds), Farmacologia Aplicada à Medicina Veterinária. $4^{\mathrm{a}}$ ed. Guanabara Koogan, Rio de Janeiro.

Crispie F., Flynn J., Ross R.P., Hill C. \& Meaney W.J. 2004. Dry cow therapy with a non-antibiotic intramammary teat seal: A review. Irish Vet. J. 57(7):412-418.

Dosogne H., Hoeben D., Burvenich C. \& Lohuis J.A.C.M. 1998. Effect of cephapirin and mecillinam on the phagocytic and respiratory burst activity of neutrophil leukocytes isolated from bovine blood. J. Vet. Pharmacol. Therap. 21:421-427.

Fox L.K., Hancock D.D. \& Horner S.D. 1992. Selective intramammary antibiotic therapy during the nonlactating period in goats. Small Rumin. Res. 9:313-318.

Gonzalo C., Tardaguila J.A., De La Fuente L.F. \& San Primitivo F. 2004. Effects of selective and complete dry therapy on prevalence of intramammary infection an on milk yeld in the subsequent lactation in dairy ewes. J. Dairy Res. 71:33-38.

Hoeben D., Burvenich C. \& Heyneman R. 1997. Influence of antimicrobial agents on bactericidal activity of bovine milk polymorphonuclear leukocytes. Vet. Immunol. Immunopathol. 56(3/4): 271-282.

International Dairy Federation 2003. Ruminant Mammary Gland Immunity. International Dairy Federation, Brussels, p.10-13.

Lintner T.J. \& Eberhart R.J. 1990. Effect of bovine mammary secretion during the early nonlactating period and antibiotics on polimorphonuclear neutrophil function and morphology. Am. J. Vet. Res. 51(4): 524-532.

Mcdougal S. \& Anniss F. 2005. Efficacy of antibiotic treatment at dryingoff in curing existing infections and preventing new infections in dairy goats, p.523-528. In: Hogeveen H. (Ed.), Mastitis in Dairy Production. Wageningen Academic Press Publ., Netherlands.

Nickerson S.C., Paape M.J., Harmon R.J. \& Ziv G. 1986. Mammary leukocyte response to drug therapy. J. Dairy Sci. 69:1733-1742.

Paape M.J., Lilius E.M., Wiitanen P.A., Kontio M.P. \& Miller R.H. 1996. Intramammary defense against infections induced by Escherichia coli in cows. Am. J. Vet. Res. 57:477-482.

Paape M.J., Contreras A. \& Ledbetter T.K. 2004. Variation among goats in the ability of their polymorphonuclear neutrophil leukocytes and mammary secretions to support phagocytosis: Inhibitory effects of milk fat globules. Small Rumin. Res. 54:183-189.

Rainard P. \& Poutrel B. 2000. Generation of complement fragment C5a in milk is variable among cows. J. Dairy Sci. 83:945-951.

Tian S.Z., Chang C.J., Chiang C.C., Peh H.C., Huang M.C., Lee J.W. \& Zhao X. 2005. Comparsion of morphology, viability, and function between blood and milk neutrophils from peak lactatin goats. Canadian J. Vet. Res. 69:39-45.

Tizard I.R. 2004. Veterinary Immunology: An introduction. $7^{\text {th }}$ ed. Roca, São Paulo, p.24-48. 